OPEN ACCESS

Edited by:

Uri Kopylov,

Sheba Medical Center, Israel

Reviewed by:

Kostas Katsanos,

University Hospital of Ioannina, Greece

Miles Sparrow,

The Alfred Hospital, Australia

*Correspondence:

Viviana Laredo

vlaredodelatorre@gmail.com

Carla J. Gargallo-Puyuelo

carlajerusalen@hotmail.com

tThese authors have contributed equally to this work and share first authorship

Specialty section:

This article was submitted to

Gastroenterology,

a section of the journal

Frontiers in Medicine

Received: 17 March 2021

Accepted: 23 June 2021

Published: 16 July 2021

Citation:

Gargallo-Puyuelo CJ, Laredo V and

Gomollón F (2021) Thiopurines in Inflammatory Bowel Disease. How to Optimize Thiopurines in the Biologic

Era? Front. Med. 8:681907.

doi: 10.3389/fmed.2021.681907

\section{Thiopurines in Inflammatory Bowel Disease. How to Optimize Thiopurines in the Biologic Era?}

\author{
Carla J. Gargallo-Puyuelo ${ }^{1 \star t}$, Viviana Laredo ${ }^{1 \star t}$ and Fernando Gomollón ${ }^{1,2,3,4}$ \\ ${ }^{1}$ Department of Gastroenterology, University Clinic Hospital Lozano Blesa, Zaragoza, Spain, ${ }^{2}$ Department of Medicine, \\ Psychiatry and Dermatology, University of Zaragoza, Zaragoza, Spain, ${ }^{3}$ Institute for Health Research Aragón (IIS Aragón), \\ Zaragoza, Spain, ${ }^{4}$ Centro de Investigación Biomédica en Red, Enfermedades Hepáticas y Digestivas, Madrid, Spain
}

Thiopurines have been a cornerstone in the treatment of inflammatory bowel disease (IBD). Although they have been used for more than 50 years, there are still some unsolved issues about their efficacy and, also, some safety concerns, mainly the risk of myelosuppression and life-threatening lymphoproliferative disorders. Furthermore, the development of biological therapy raises the question whether there is still a role for thiopurines in the IBD treatment algorithm. On the other hand, limited cost and wide availability make thiopurines a reasonable option in settings of limited resources and increasing prevalence of IBD. In fact, there is a growing interest in optimizing thiopurine therapy, since pharmacogenomic findings suggest that a personalized approach based on the genotyping of some molecules involved in its metabolism could be useful to prevent side effects. Polymorphisms of thiopurine methyltransferase enzyme (TPMT) that result in low enzymatic activity have been associated with an increased risk of myelotoxicity, especially in Caucasians; however, in Asians it is assumed that the variants of nudix hydrolase 15 (NUDT15) are more relevant in the development of toxicity. Age is also important, since in elderly patients the risk of complications seems to be increased. Moreover, the primo-infection of Epstein Barr virus and cytomegalovirus under thiopurine treatment has been associated with severe lymphoproliferative disorders. In addition to assessing individual characteristics that may influence thiopurines treatment outcomes, this review also discusses other strategies to optimize the therapy. Low-dose thiopurines combined with allopurinol can be used in hypermethylators and in thiopurine-related hepatotoxicity. The measurement of metabolites could be useful to assess compliance, identify patients at risk of adverse events and also facilitating the management of refractory patients. Thioguanine is also a rescue therapy in patients with toxicity related to conventional thiopurine therapy. Finally, the current indications for thiopurines in monotherapy or in combination with biologics, as well as the optimal duration of treatment, are also reviewed.

Keywords: thiopurines, inflammatory bowel disease, pharmacogenomics, toxicity, indications, optimize 


\section{INTRODUCTION}

Inflammatory bowel disease (IBD) includes mainly two chronic disorders affecting the gastrointestinal tract, Crohn's disease (CD) and ulcerative colitis (UC), and it has a worldwide distribution (1). The medical treatment is based on 5-aminosalicylates, corticosteroids, immunomodulators (thiopurines and methotrexate) and biologics $(2,3)$.

Thiopurines (azathioprine, mercaptopurine and thioguanine) are antimetabolites of purines which have been a cornerstone in the treatment of IBD for more than 50 years (4). In spite of that, there is still lack of evidence about its efficacy in some scenarios. Firstly, guidelines do not recommend using thiopurines (TP) as induction therapy $(2,3,5-7)$. In $\mathrm{CD}$ most evidence comes from studies comparing azathioprine (AZA) and placebo (8); and there is only one randomized controlled trial comparing AZA and biologic therapy (infliximab), concluding that AZA was inferior (9). Although the quality of the studies has been questioned, the evidence for AZA as induction therapy in UC is also absent $(7,10)$. In maintaining of remission, there are Cochrane reviews of randomized controlled trials for both, $\mathrm{CD}$ and UC, demonstrating a superiority of AZA against placebo; however, the quality of evidence is again low, especially in UC $(11,12)$. Another common indication is the prevention of postsurgical relapse, but despite the fact that it seems to be superior to placebo, there is a wide heterogeneity in the designs of studies and in one small randomized trial comparing AZA with biologics (adalimumab) there were no differences in efficacy between both treatments while in other study adalimumab was superior (5, $13,14)$. Finally, the evidence supporting combination therapy of AZA with biologics relays mainly on two prospective trials in which combination therapy was superior to monotherapy in $\mathrm{CD}$ and UC $(9,15)$. Despite the superiority, the appropriate duration of combination therapy is still unknown $(5,7)$.

In addition to unsolved efficacy issues, safety concerns may also limit the use of TP in clinical practice. The rate of adverse events is up to $25 \%$ in some studies and nearly $20 \%$ of patients have to discontinue the treatment (16). Some strategies, as periodic blood tests, determination of genetic polymorphisms and metabolites measurement, are useful to decrease the risk of some side effects such as myelotoxicity, but it cannot be prevented in all cases and it can occur at any time of the treatment (17). Although it could be a serious adverse event, the risk of death due to myelotoxicity is relatively low (1\%) (18). Other uncommon life-threatening hematological conditions, such as hemophagocytic lymphohistiocytosis (HLH) and other lymphoproliferative disorders have also been associated with TP (19). Pancreatitis and hepatotoxicity are other limiting side effects related to TP $(20,21)$.

Despite efficacy issues, toxicity risks and the availability of other therapeutic options, there are some arguments in favor of optimizing TP. Firstly, the epidemiological evolution of IBD is changing and pediatric onset of the disease is becoming more common in some Western countries $(1,22)$, which implies a longer evolution of the disease in these patients and, probably, the need for different IBD treatments during their life; especially considering that the course of the disease seems to be more aggressive (23). In spite of the availability of many therapeutic options for IBD, there are still some refractory patients who will eventually need surgery (24); therefore, optimizing medical treatment before escalation seems a reasonable option. Furthermore, due to the increasing prevalence of IBD in Western countries, the number of patients in IBD units and, consequently, the treatment-related costs are expected to increase $(1,25)$. TP are cheaper compared to biologics; in fact, in some countries, before the biologics, the cost of drugs represented 25\% of the IBD care cost and, after them, the cost has increased from 30 to $70 \%$ (26). Finally, the overall efficacy of TP has been demonstrated for many years and, in general, patients who respond to these drugs tend to maintain a long remission $(4,27)$. Clinical experience with TP also helps to manage most side effects, and those that are life-threatening are uncommon.

\section{HOW TO IMPROVE EFFICIENCY OF THIOPURINES?}

\section{Using the Treatment in Selected Patients Depending on Individual Characteristics Pharmacogenomics}

AZA is a prodrug and, after a non-enzymatic change, $88 \%$ of it is converted into mercaptopurine (MP), that can be metabolized through different pathways into another active and inactive metabolites, as shown in Figure $1(27,28)$. The thiopurine methyltransferase enzyme (TPMT) methylates MP into methylmercaptopurine (MMP), an inactive metabolite associated with some adverse events, mainly hepatotoxicity. MP can also be oxidized by xanthine oxidase into thiouric acid (TUA), another inactive degradation product. However, MP can be converted by hypoxanthine-guanine phosphoribosyltransferase (HPRT) into thiosine monophosphate (TIMP), which can also be transformed by 5 - inosine monophosphate dehydrogenase (5-IMPDH) into thioguanine monophosphate (TGMP) and, then, into thioguanine diphosphate (TGDP) and triphosphate (TGTP) (28). Thioguanine (TG) is also metabolized by HPRT into TGMP. TGMP, TGDP and TGTP are thioguanine nucleotides (TGNs) and the active metabolites of AZA, responsible for the efficacy and myelotoxicity of TP. These nucleotides antagonize the endogenous purines and incorporate into cellular RNADNA, inhibiting cellular proliferation. Other mechanism of action includes inhibition of Rac1 activation with costimulation of CD28 leading to $\mathrm{T}$ cell apoptosis (29). The main action of TPMT enzyme is to methylate MP, TG, TIMP and TGMP; so they become inactive products, TGNs synthesis decreases and, subsequently, TP are less effective (30). Efficacy and side effects are consequence of a tight balance between the pathways that activate and inactive TP and a wide inter-individual variability has been described in this setting (31).

Currently, more and more studies highlight the role of pharmacogenomics in optimizing TP (31-33). Polymorphisms of TPMT, nudix hydrolase 15 (NUDT15), alpha-ketoglutarate dependent dioxygenase (FOT), class II HLA and inosine triphosphate pyrophosphatase (ITPA) have been associated with an increased risk of adverse events (Table 1). 


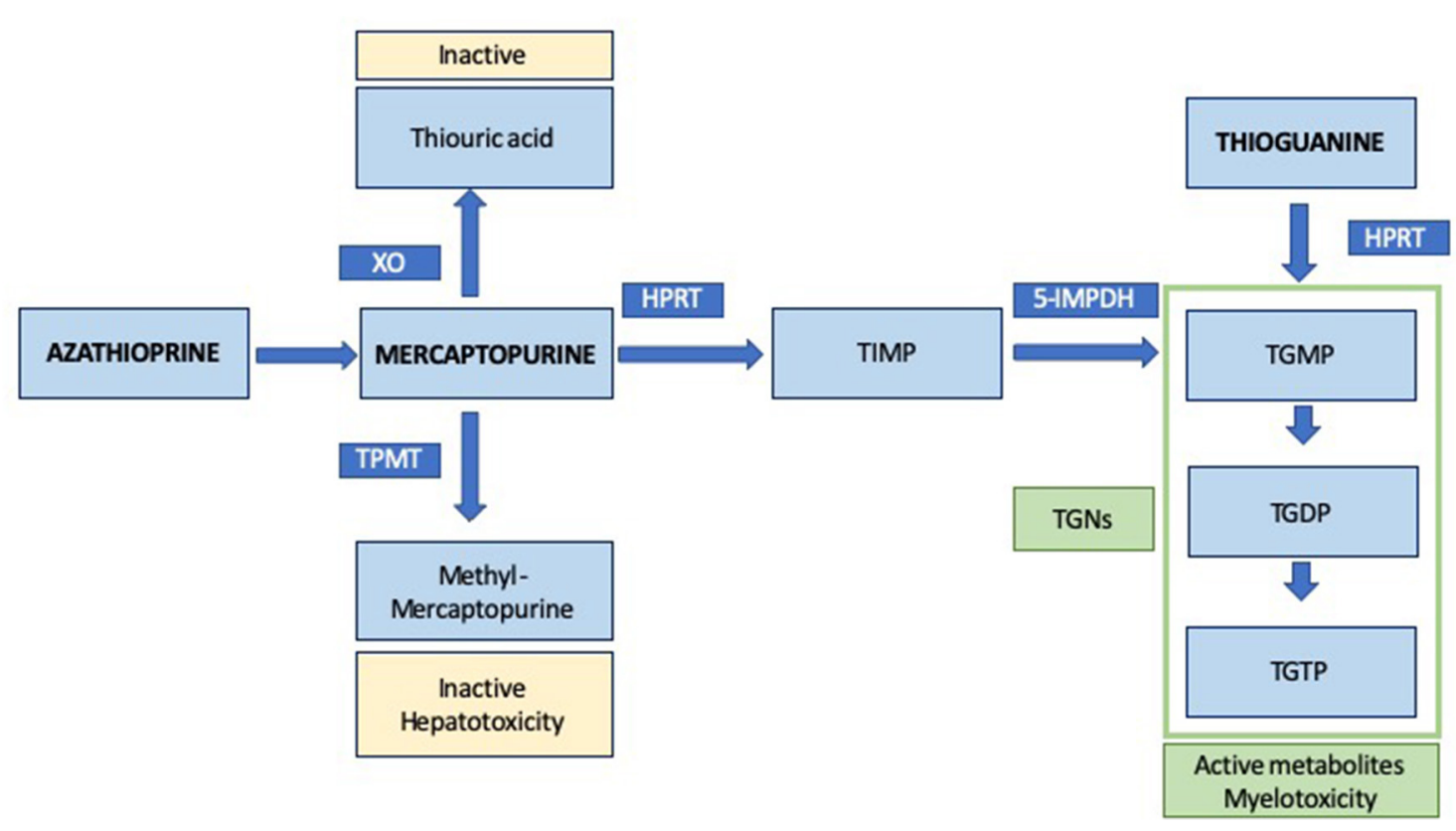

FIGURE 1 | Simplified metabolism of thiopurines. XO, xanthine oxidase; TPMT, thiopurine methyltransferase; HPRT, hypoxanthine-guanine phosphoribosyltransferase; 5-IMPDH, 5- inosine monophosphate dehydrogenase; TIMP, thiosine monophosphate; TGNs, thioguanine nucleotides; TGMP, thioguanine monophosphate; TGDP, thioguanine diphosphate; TGTP, thioguanine triphosphate.

TABLE 1 | Most important genetic variants associated with thiopurine toxicity.

\begin{tabular}{|l|l|l|}
\hline Genetic variant & Functional consequence & Clinical consequence \\
\hline $\begin{array}{l}\text { TPMT*2 (rs1800462) } \\
\text { TPMT*3C (rs1142345) } \\
\text { TPMT*3A: contains *3B (rs1800460) and } \\
{ }^{*} \text { 3C (rs1142345) }\end{array}$ & Low TMPT enzymatic activity & \\
\hline $\begin{array}{l}\text { NUDT15 } \\
\text { p.Arg139Cys or c415C>T (rs116855232) }\end{array}$ & Low NUDT15 enzymatic activity & Risk of myelotoxicity \\
\hline NUDT15 p.Val18_Val19insGlyVal allele & Low NUDT15 enzymatic activity & Risk of myelotoxicity \\
\hline Class II HLA polymorphism (rs2647087) & Unclear & Risk of pancreatitis \\
\hline ITPA & Low enzymatic activity & Inconclusive data about increased risk of \\
\hline 94C $>$ A (rs1127354) & & side effects \\
\hline FTO & Low enzymatic activity & Leukenia \\
\hline Ala134Thr (rs79206939) & & \\
\hline
\end{tabular}

\section{Thiopurine Methyltransferase}

Patients with increased TPMT activity are called "hypermethylators" or "non-responders" because they mainly produce methylated inactivated products of AZA with very low amounts of active metabolites (34). On the other hand, patients with low-activity in both alleles of TPMT gene mainly produce active metabolites by increasing IMPDH pathway and are at risk of severe adverse events, especially myelotoxicity. The TPMT alleles can be classified into functional $\left({ }^{*} 1\right)$ or non-functional $\left({ }^{*} 2,{ }^{*} 3 \mathrm{~A},{ }^{*} 3 \mathrm{~B},{ }^{*} 3 \mathrm{C},{ }^{*} 4\right)(35)$. There are many different polymorphisms associated with low TPMT activity but the most important are $\mathrm{TPMT}^{*} 2$, TPMT* $3 \mathrm{~A}$ and $\mathrm{TPMT}^{*} 3 \mathrm{C}$, as they represent $60-95 \%$ deficient alleles in most populations (31). Depending on genotype, patients could be classified into homozygous of high activity alleles (two or more functional alleles), heterozygous with intermediate activity (one functional allele and one non-functional) and homozygous with low activity (two non-functional alleles). In Caucasians, $0.3 \%$ are homozygous for low activity alleles, $11 \%$ are heterozygous and $89 \%$ are homozygous for high activity alleles (36). Based on the genotype, a full dose of TP is recommended in high activity homozygous, a 50\% dose-reduction in heterozygotes, and avoiding treatment in low activity homozygous $(35,37)$. TPMT activity can be measured using phenotype in red blood cells or genotype, based on the analysis of polymorphisms associated with low TPMT activity (38). Genotype appears to be superior to phenotype, as it better identifies heterozygous with similar rates by misclassifying TPMT defectives (39). On the other hand, one advantage of TPMT phenotype, rather than genotype, is that within one genotype there can be significant 
variation in phenotypes, allowing for further individualization of dosing.

Despite the theoretical utility of TPMT genotyping, the TOPIC trial did not find an advantage of this strategy to reduce the incidence of myelotoxicity (37), except in heterozygotes with high-risk variants of TPMT, while the TARGET trial did not find a benefit in this subgroup of patients (40). The correct management of heterozygous is also controversial. Studies suggest that $30-60 \%$ of patients with intermediate TPMT activity will develop myelotoxicity under full dose of thiopurines, therefore the guidelines recommend a dosereduction in heterozygotes; however, if we guide treatment only by TPMT activity, $40 \%$ of patients will be undertreated $(31,32)$. Furthermore, only $25 \%$ of myelosuppression can be explained by a TPMT deficiency (41).

The benefit of routinely testing TPMT is unclear (42). Some societies, such as the American Gastroenterological Association (43) and the British Society of Gastroenterology (6), recommend testing TPMT routinely before starting TP, but with low quality of evidence, while others, such as the Spanish Working Group on Crohn's and Ulcerative Colitis (GETECCU) or the European Crohn's and Colitis Organization (ECCO) support this recommendation, but suggest that is not essential before starting treatment $(3,5)$. Regarding the cost of routine TPMT testing, some authors suggest that it is cost-effective $(33,38)$ and others conclude that genotyping is a cost-neutral strategy (44). If available, it seems reasonable to test TPMT before starting TP; however, it may also depend on the prevalence of homozygous and heterozygous in each population (18). Moreover, periodic blood tests are mandatory throughout treatment because the risk of myelotoxicity does not disappear (42).

\section{Nudix Hydrolase 15}

The incidence of leukopenia under TP therapy ranges from 3\% in Caucasians (18) to $40 \%$ in Koreans (45), probably due to polymorphisms in genes responsible for TP metabolism (46). TPMT polymorphisms are less common in Asians than in Caucasians (47); even when leukopenia rates are higher, therefore genotyping TPMT in Asians is not so useful (48). Moreover, even in Caucasians, only a small part of myelotoxicity can be explain by TPMT polymorphisms (49), implying that other genes could play an important role in the development of toxicity. Recent studies suggest that genes like NUDT15 and FTO are associated with some cases of myelotoxicity, especially in Asians, although this association has also been identified in Caucasians (50).

Despite of the fact that the mechanism of action of NUDT15 is not well understood, it is probably responsible for the inactivation of TGNs (49), participating in the degradation of TGTP into TGMP, avoiding the incorporation of thioguanine nucleotides into cellular DNA and reducing some effects of TP (51). NUDT15 variants associated with low enzymatic activity do not change the total amount of TGNs but modify the ratio of TGTP and TGMP (49); therefore monitoring the levels of TGTP and TG integrated into the DNA could be useful to adjust the dose of TP in patients with NUDT15 deficiency (52). Although measurement of individual 6TGNs-6TGMP, 6TGDP, and 6TGTP- would be preferable as it is mentioned, these assays are not widely available.

Patients with genetic variants of NUDT15 resulting in low activity are at risk of developing toxicity, even those with intermediate activity. In Koreans, there is a variation in NUDT15 (rs116855232, mainly called p.Arg139Cys or $4415 \mathrm{C}>\mathrm{T}$ ) that has a $89.4 \%$ sensitivity and $93.2 \%$ specificity for TP leukopenia (53). Studies suggest that virtually all patients homozygous for p.Arg139Cys will develop severe leukopenia; however, other diplotypes could also result in low enzymatic activity. Therefore, testing for p.Arg139Cys could be useful to avoid the treatment in homozygous; however, if we want to find the ideal initial dose of TP for each patient, the study of diplotypes may be necessary (54). In this way, the p.Val18_Val19insGlyVal allele is another variant of NUDT15 associated with low enzymatic activity (49). Homozygous or compound heterozygous for highrisk variants of NUDT15 are more likely to develop toxicity than those carrying intermediate or normal activity diplotypes. There are many possible combinations of these alleles and the clinical consequences can be very different, so the application of NUDT15 activity in the TP algorithm is challenging.

In Japan almost $25 \%$ of population carry one copy of the NUDT15 risk alleles and 2\% are homozygous or compound heterozygous (52). The ethnic distribution of p.Arg139Cys varies from $9.8 \%$ in East Asians to $0.2 \%$ in Europeans (55). Clinical relevance also varies between populations; for example, in Chinese the risk variants of NUDT15 are supposed to be one of the most relevant in the development of toxicity (51); however, in Guatemalans these variants are not so important (49). These results suggest that ethnicity is probably one of the most important risk factors for developing toxicity under TP treatment.

A randomized controlled trial in Koreans analyzed the influence of genotyping NUDT15 before starting treatment (56). In heterozygous, they used $50 \mathrm{mg}$ of AZA and, in homozygous, the treatment with TP was avoided. The rest of patients (wild type and controls) followed a stepped dose strategy. In this study, genotyping before starting treatment decreased the risk of toxicity (HR $=0.37 ; 95 \%$ CI: $0.18-0.77 ; p=0.008$ ). These results encouraged the authors to propose a similar algorithm to manage TP therapy more efficiently based on NUDT15 genotyping. They strongly recommend avoiding TP in NUDT15 homozygous.

\section{Other Genetic Polymorphisms}

In Asians, a polymorphism of FTO gene (rs79206939 or Ala134Thr) has been associated with a $65 \%$ decrease in its enzymatic activity and an increased risk of leukopenia (56, 57), while another polymorphism of this gene ( $\mathrm{rs} 16952570$ CC genotype) could have a protective impact on the risk of myelotoxicity (58). Moreover, the class II HLA rs2647087 polymorphism has been associated with an increased risk of pancreatitis $(59,60)$. In homozygous $(\mathrm{C} / \mathrm{C})$ the risk is significantly higher (14.63\%), than in heterozygous (A/C) $(4.25 \%)$ or wild type $(\mathrm{A} / \mathrm{A})(0.53 \%)$; therefore, some authors recommend avoiding TP in homozygous and, if possible, also in heterozygous (60). 
As previously mentioned, the inhibition of Racl activation leads to T-cell apoptosis. The Rac 1 rs34932801 polymorphism has been associated with a poor response to thiopurine therapy (61). There are also inconclusive data regarding inosine triphosphate pyrophosphatase (ITPA) polymorphisms [94C > A (rs1127354) and IVS2 $+21 \mathrm{~A}>\mathrm{C}$ ] resulting in low enzymatic activity leading to increased 6-TGN levels and thiopurine-related toxicity $(31,62,63)$.

\section{Other Personal Risks \\ Age}

Since, in some studies, up to $20 \%$ of patients are diagnosed of IBD at age 60 or older, new treatments improve survival and the aging of population, an increase in the number of elderly patients with IBD is expected (64). In this subgroup of patients there is concern about starting treatment with immunomodulators and biologics due to the theoretical increased risk of neoplasms, adverse events and drug interactions (65). In fact, Parian et al. found that patients older than 65 years could take an average of nine chronic drugs and, in $40 \%$ of them, there was a potential interaction between IBD therapy and chronic treatment (66).

In a recent study, patients who started TP over 60 years of age had significantly more adverse events (43.4 vs. $29.7 \%$; $p<0.01$ ), infections ( 3.6 vs. $2.0 \%$; $p<0.001$ ) neoplasms ( 1.5 vs. $0.2 \%$; $p<$ 0.001 ), myelotoxicity ( 14 vs. $7.6 \%, p<0.01$ ), hepatotoxicity ( 9 vs. $4.7 \%, p<0.001)$ and digestive intolerance ( 12.3 vs. $10 \%$; $p=$ 0.002 ), than the younger ones (65). In another study, the risk of malignancy and mortality was higher in elderly patients treated with TP than in those with anti-TNF therapy $(\mathrm{H}=3.017 ; 95 \% \mathrm{CI}$ : $1.050-8.666 ; p=0.0403$ and $\mathrm{HR}=3.682 ; 95 \% \mathrm{CI}: 1.192-11.377$; $p=0.0235$, for malignancy and mortality, respectively) (67). Regarding neoplasms, in the prospective observational CESAME study, the rate of urinary tract cancer in patients receiving TP was $0.48 / 1,000$ patient-years (68). Male sex $(\mathrm{HR}=3.98, p=0.04)$ and age over 65 years $(\mathrm{HR}=13.26, p=0.0001)$ were the main risk factors.

\section{Viral Infections (Epstein-Barr Virus and Cytomegalovirus Serological Status)}

The primo-infection of Epstein-Barr virus (EBV) in young patients treated with TP has been associated with an increased risk of HLH (69). There are also some case reports about the relationship between cytomegalovirus (CMV) and HLH or severe primo-infection in patients under thiopurine therapy (70, 71). In a recent study, exposure to TP was an independent risk factor for developing serious viral infections, mainly caused by CMV or EBV (72). After EBV infection, the virus can be reactivated and, under normal conditions, the T-lymphocytes can neutralize it; however, under TP therapy, these lymphocytes are unable to act and an uncontrollable proliferation could lead to the development of complications (69). A Spanish group found that 97.4\% of IBD patients were EBV-IgG positive and, among the negative ones, the seroconversion rate was $29.7 \%$ during 4 years of follow-up, without differences between young and elderly patients; therefore, EBV serological status should be assessed, regardless of age or sex, in all patients before starting TP (69).
In a meta-analysis, the risk of lymphoma was higher in patients treated with combination therapy than in those with TP o anti-TNF monotherapy $(\mathrm{RR}=1.10 ; 95 \% \mathrm{CI}: 1.03-2.81$; $p=0.039$ ) (73). It could be explained by an additive effect: TP affect the activity of T-lymphocytes, anti-TNFs decrease the action of natural killers and both help to propagate the lymphoblastoid transformation initiated by $\operatorname{EBV}(73,74)$. In addition, the results of a recent study suggest that the risk of EBV-related lymphoma could be increased in patients with low thiopurine therapy compliance, since under the treatment there is an inhibition of cell replication, but after discontinuing it, an increase in the number of B-cells and lymphoblastoids can led to uncontrollable proliferation (74). Patients with exposure to TP have a five times higher risk of lymphoproliferative disorders than those who are not treated with these drugs; however, the 10-years risk of developing these disorders in young patients is $<1 \%$ (75). Moreover, in a recent study, the incidence of acute myeloid leukemia and/or myelodysplastic syndrome was 18.7 per 100,000 IBD patients-year (76). The risk was increased in patients with current TP therapy but not in those with previous exposure. Based on the data above, ECCO guidelines recommend assessing EBV serological status before starting immunosuppressive therapy (77) and balancing the risk-benefit and the availability of other compounds we recommend avoiding thiopurines in EBV-IgG negative patients, particularly in young males. Despite the increased risk of lymphoproliferative disorders associated with TP, it is important to note that these drugs have also been associated with a reduction in the incidence of colorectal cancer, due to different mechanisms not only related to its anti-inflammatory effect (78).

\section{Using Low Dose Thiopurine and Allopurinol}

Allopurinol is a xanthine oxidase inhibitor and when added to TP increases its metabolism through 5-IMPDH into 6TGN. LDTA can be useful in "hypermethylators" (79), in which TGN levels are usually $<230-400 \mathrm{pmol} / 8 \times 10^{8}$ and/or 6-MMP levels are over 5,700-6,000 pmol/8 $/ 810^{8}$ (80), so that they are at risk of hepatotoxicity and refractoriness to TP (81).

The increase in the levels of active metabolites can lead to myelotoxicity; therefore a $25-50 \%$ reduction in the dose of TP has been proposed to prevent it (82). In some studies, the dose of allopurinol ranges from 50 to $100 \mathrm{mg}$ per day (80), however recent evidence suggests a clinical benefit without increasing toxicity using $100 \mathrm{mg}$ (83). Some authors also suggest adjusting the dose of combination therapy based on TGN levels 4 weeks after starting treatment, 4 weeks after any dose change and every 6-12 months (81).

The efficacy of LDTA in non-responders and also in patients with TP-related hepatotoxicity has been demonstrated $(81,83$, 84). In a recent randomized clinical trial, clinical response to LDTA was observed from week 2 of therapy, suggesting a faster onset of action, probably due to a rapid increase in TGN levels (83). Allopurinol is usually well-tolerated, with no major side effects, with skin rashes and gastrointestinal symptoms being the 
most common. Toxic epidermal necrolysis has been described in Asians (81).

\section{Adjusting Dose of TP Depending on Metabolites}

The measurement of TP metabolites (TGN and MMP) can be useful to assess compliance, identify patients at risk of adverse events and also to manage refractory patients as shown in Table 2 (31); however, the efficacy and toxicity thresholds are still unclear (42).

It has been suggested that the TGN target levels are likely to depend on the situation. When TP are used as monotherapy, TGN levels above $230-235 \mathrm{pmol} / 8 \times 10^{8} \mathrm{RBC}$ have been associated with clinical response, and more than $450 \mathrm{pmol} / 8$ $\times 10^{8} \mathrm{RBC}$ have been associated with an increased risk of myelotoxicity $(5,85)$. Regarding mucosal healing, a cutoff level of $397 \mathrm{pmol} / 8 \times 10^{8} \mathrm{RBC}$ has been proposed with high specificity but low sensibility ( 86.7 and $35.3 \%$, respectively) (86). In Chinese patients, a cutoff point between 180 and $355 \mathrm{pmol} / 8 \times 10^{8} \mathrm{RBC}$ has been associated with remission (87). If the goal is to decrease immunogenicity related to anti-IFX antibodies, TGN levels $\geq 120$ $\mathrm{pmol} / 8 \times 10^{8} \mathrm{RBC}$ appear to be enough to significantly reduce antibodies (88). In other studies, a similar cutoff (105-125 pmol/8 $\times 10^{8} \mathrm{RBC}$ ) was also associated with maintenance of therapeutic IFX levels $(89,90)$.

High levels of MMP have been associated with thiopurinerelated hepatotoxicity (91-93). Moreover, in one study, patients with MMP levels between 3,615 and 5,700 $\mathrm{pmol} / 8 \times 10^{8} \mathrm{RBC}$ had a 4-fold risk of hepatotoxicity (85); however, subsequent studies did not confirm this association (21). In fact, in one study almost $90 \%$ of patients with high concentration of MMP did not develop hepatotoxicity and, in $40 \%$ of patients with hepatotoxicity, MMP levels were below the risk cutoff (21). Therefore, it seems that high levels of MMP should be associated with other alterations, such as hypertransaminasemia, to be considered a marker of hepatotoxicity (94).

The overall benefit of routine metabolite monitoring remains unclear (42), since some studies do not find a benefit $(95,96)$ while others consider it as a strategy to optimize TP before switching to biologics $(91,97,98)$. Data on the cost-effectiveness of this strategy is also insufficient (42).

\section{Using Thioguanine}

TG is a thiopurine with a simpler metabolism than AZA or MP. In a single pathway by HPRT, TG is transformed into TGNs, thus the methylated products associated with toxicity are not produced (99). Moreover, an experimental study in mice suggests that the effects of TG do not depend only on lymphocyte inactivation, because TG can be transformed into TGNs by the local action of colonic mucosal cells and colonic microbiota, leading to autophagy and intracellular destruction of bacteria (100). In fact, TGNs appear to accumulate in areas of intestinal inflammation, which explains the faster onset of the effect and could decrease lymphocyte-related myelotoxicity.

In terms of efficacy, $\sim 65 \%$ of patients previously treated with AZA or MP, have clinical response with TG (101) and, in one study, in $57 \%$ of patients the addition of TG to antiTNF therapy led to an improvement in the clinical situation (102). Efficacy seems to be similar to LDTA and discontinuation rates due to adverse events do not differ from conventional TP $(16,103)$. However, the main limitation of TG has been the risk of hepatotoxicity, especially the risk of nodular regenerative hyperplasia, which may be dose-related, since high doses of TG (40 mg/day) have been associated with liver injury (104), whereas studies using lower doses $(20 \mathrm{mg} /$ day $)$ did not find a significant risk of this side effect and the efficacy was similar $(99,105-$ 108). Furthermore, in another study the development of biopsydiagnosed nodular regenerative hyperplasia was not associated with significant clinical consequences in most patients (109).

\section{INDICATIONS OF THIOPURINES IN IBD IN THE BIOLOGIC ERA}

\section{Thiopurines as Monotherapy}

\section{Evidence in Crohn's Disease}

$\mathrm{TP}$ as monotherapy seem to be inefficient for induction of clinical remission in active luminal CD and more recent clinical guidelines suggest against their use for this indication based on very low-quality evidence. Five placebo-controlled studies involving 380 patients have evaluated TP in this indication using validated outcomes measures (CDAI $<150$ or $\mathrm{HBI} \leq 3$ ). The use of concomitant steroids was allowed in four of them. The pooled analysis (intention-to-treat basis) showed no differences between $\mathrm{TP}$ and placebo for induction of remission ( 48 vs. $37 \%, \mathrm{RR}=$ 1.23; 95\% CI: 0.97-1.55) (110-114). Three trials have evaluated clinical response (not using validate outcomes measures) and no differences were found between $\mathrm{TP}$ and placebo $(\mathrm{RR}=1.87$, $95 \%$ CI: $0.44-7.96)$. Heterogeneity was serious in this case $\left(I^{2}=\right.$ $69 \%$ ) and imprecision very serious due to sparse data and wide confidence intervals; being the quality of evidence very low for this outcome (115-117).

However, effectiveness of TP as maintenance treatment for steroid-dependent luminal $\mathrm{CD}$ has been consistently proven. A 2015 Cochrane systematic review, which included six trials published between 1971 and 2013, showed that AZA was superior to placebo for the maintenance of remission $(73 \%$ of patients treated with AZA remained in remission compared to $62 \%$ of those who were treated with placebo, $R R=1.19 ; 95 \%$ CI: $1.05-$ 1.34). Probably these figures underestimate the efficacy because the meta-analysis included studies with infra-therapeutic doses $(<2 \mathrm{mg} / \mathrm{kg} /$ day), but also is important to note that the number of patients included was modest (489) and follow up was limited (618 months) (11). The effect of TP on fistula healing in complex perianal CD has been reported in RCT in very few patients and, therefore, there is no evidence that support its use as monotherapy in this scenario. Very interesting is a recent largescale study whose results suggest a re-evaluation of the place for TP monotherapy in the maintenance treatment algorithm in CD. Stournaras et al. study assessed the long-term effectiveness of TP monotherapy with the intention of maintaining medically induced remission in 11,928 patients $(4,968 \mathrm{UC}, 6,960 \mathrm{CD})$. TP were effective, without the need for escalation to biologic therapy 
TABLE 2 | Thiopurine monitoring based on metabolites.

\begin{tabular}{|l|l|l|l|l|}
\hline 6-TGN & 6-MMP & Cause & Consequences & Recommendation \\
\hline Normal or high & Low & $\begin{array}{l}\text { Therapeutic dose } \\
\text { Refractoriness if absence of response }\end{array}$ & $\begin{array}{l}\text { Control of disease activity } \\
\text { No control of disease activity }\end{array}$ & $\begin{array}{l}\text { Continue therapy } \\
\text { Change therapy }\end{array}$ \\
\hline High & High & Overdose & $\begin{array}{l}\text { Myelotoxicity } \\
\text { Hepatotoxicity } \\
\text { No control of disease activity }\end{array}$ & Reduce dose \\
\hline High & Row & $\begin{array}{l}\text { Low TPMT activity } \\
\text { Refractoriness if absence of response } \\
\text { Response }\end{array}$ & $\begin{array}{l}\text { Risk of myelotoxicity } \\
\text { No control of disease activity } \\
\text { Control of disease activity }\end{array}$ & $\begin{array}{l}\text { Reduce dose } \\
\text { Change therapy } \\
\text { Continue monitoring }\end{array}$ \\
\hline Low & Highermethylators & $\begin{array}{l}\text { No control of disease activity } \\
\text { Hepatotoxicity }\end{array}$ & $\begin{array}{l}\text { Reduce dose (25-50\%) and add } \\
\text { allopurinol }\end{array}$ \\
\hline Low & Low & $\begin{array}{l}\text { Underdose control of disease activity } \\
\text { No compliance }\end{array}$ & $\begin{array}{l}\text { Increase dose } \\
\text { Assess adherence }\end{array}$ \\
\hline
\end{tabular}

6-TGN levels: low $\left(<230-235 \mathrm{pmol} / 8 \times 10^{8}\right)$, high $\left(>450 \mathrm{pmol} / 8 \times 10^{8}\right)$, normal $\left(230-450 \mathrm{pmol} / 8 \times 10^{8}\right)$.

6-MMP levels: high $\left(>5,700 \mathrm{pmol} / 8 \times 10^{8}\right)$, low $\left(<5,700 \mathrm{pmol} / 8 \times 10^{8}\right)$.

or need for surgery, in both UC and CD, but its efficacy was significantly lower in CD patients than in UC patients $(34.2$ vs. 52.7\%) (118). The data summarized by Verstockt et al. on the Leuven hospital experience are less hopeful. Among 780 patients included with $\mathrm{CD}$, only a small proportion of patients (7.5\%, 59 patients) continued TP monotherapy till final follow-up (median of 13 years), suggesting that even in this widely accepted indication its long-term role is limited (119).

Another common use of TP is prevention of post-surgical relapse in $\mathrm{CD}$. There is moderate certainty evidence that AZA and MP are superior to placebo. According to a very recent systematic review and meta-analysis (2019), after a follow-up of $12-36$ months, $51 \%$ of patients treated with AZA/MP relapsed compared to $64 \%$ of patients with placebo $(\mathrm{RR}=0.79 ; 95 \% \mathrm{CI}$ 0.67-0.92; 408 participants; three studies; IR $=0 \%$ ). Compared to anti-TNF drugs, TP seem to be inferior in this scenario but quality of evidence is very low. Cochrane review shows that after a follow-up of $12-24$ months, $43 \%$ of participants treated with AZA clinically relapsed vs. $14 \%$ of patients in the antiTNF group $(\mathrm{RR}=2.89,95 \% \mathrm{CI} 1.50-5.57,139$ participants, three studies, IR $=0 \%)(120)$.

Finally, a question that has been raised in the last decade is if the early introduction of TP could modify disease course. Two studies have evaluated this point: the AZTEC and the RAPID trials $(8,121)$. RAPID trial compared early AZA use to classical step-up therapy in patients with risk factors for serious $\mathrm{CD}$, and the AZTEC trial compared AZA with placebo up to week 76 at inducing sustained steroidfree remission in recently diagnosed uncomplicated $\mathrm{CD}$. Both studies showed no effect of early AZA, which seems to argue against its early use. However, there are some caveats, including discrepancies in disease severity between groups and outcome definitions. Interestingly, in the RAPID trial, early AZA was associated with a significant reduction in new perianal fistula and a post hoc analysis of the AZTEC showed significantly lower rate of moderate to severe $\mathrm{CD}$ relapse with early AZA therapy (12 vs. $30 \%)$. Hence, the data are not completely clear on the effects of the timing of TP initiation, but delaying initiation until irreversible complications is unlikely to maximize their benefit.

\section{Evidence in Ulcerative Colitis}

In a meta-analysis that compared TP with placebo and/or salicylates in induction of remission in UC flare, differences were not found (122). Conversely, some observational studies have reported remission rates up to $65 \%$ (CI 95\%: 55-75\%) which suggest a possible efficacy in this indication. There is solid evidence about the fact that TP requires a minimum of time to obtain efficacy (at least 1 month, in most cases more than two). Because of that, such a long latency is not acceptable when patients have a flare; current guidelines do not recommend the use of TP monotherapy as inductors of remission in UC flare (123).

Maintenance of clinical remission after a mild/moderate flare in patients with steroid-dependent/steroid-resistant UC is one of the main indications of TP. Its efficacy in this scenario has been evaluated by two meta-analysis. Gisbert et al. meta-analysis reported $60 \%$ of efficacy in controlled trials with a NNT of 5 (6 RCT included) and a 76\% of efficacy in uncontrolled studies (overall OR $=2.56,95 \%$ CI: 1.51-5.3) (122). Cochrane Institute meta-analysis that included 4 RCT with 232 patients concluded that patients treated with AZA have a lower rate of failure compared to placebo ( 44 vs. $65 \%$, respectively, $\mathrm{RR}=0.68$; $\mathrm{IC}$ 95\%: 0.54-0.86) (12). It is necessary to mention the only high quality randomized controlled trial available that compared AZA and mesalazine in steroid-dependent patients, showing that AZA is significantly more effective ( 53 vs. $21 \%$; OR $=4.78$; $95 \%$ CI: 1.57-14.5) to induce clinical and endoscopic remission and to avoid steroid requirements in the first 6 months after the flare than mesalazine (124). Additionally, probably the efficacy of TP in this trial is underestimated because it lasted only 6 months, and efficacy would not be seen in some slow TP responders. In summary, numerous observational good quality studies that include many patients followed during very long periods confirm that TP are globally effective in UC, even more than in CD (118). However, the adverse effects of TP and the efficacy and safety 
of mesalazine make it the choice in many patients. In steroiddependent patients, the superiority of TP is obvious. Also, we want to mention the first RCT that compared the efficacy of infliximab monotherapy, AZA monotherapy and combination of both drugs for UC (SUCCESS trial) (15). Panaccione et al. showed that in anti-TNF naïve patients with moderate-severe UC, the rates of steroid-free remission were significantly higher in patients with combination therapy than either agent alone (combo $39.7 \%$ vs. infliximab 22\% vs AZA 23\%). Mucosal healing at week 16 was also significantly higher in combo group $(62.8 \%)$ and infliximab alone group (54.6\%) than in patients receiving AZA alone (36.8\%).

Regarding the use of TP as maintenance treatment after severe flare, if patients were on TP treatment when severe flare occurs, subsequent maintenance with TP monotherapy after remission is very ineffective. In naïve TP patients, TP may reduce the rate of colectomy in the mid-term after severe UC flare controlled with intravenous cyclosporine, but the rate of colectomy remains very high (at least $33 \%$ a year) (125). Because of that, a more aggressive strategy by using anti-TNF drugs is more adequate to reduce the rate of colectomies to a maximum.

\section{Evidence About TP Monotherapy Withdrawal}

Whether TP can be safely interrupted in patients after achieving deep remission is a challenging question in daily practice. Patients and physicians have concerns about the long-term safety of these drugs. Seven RCT, three with placebo controlled, assessed the rate of relapse after immunomodulator withdrawal compared to continued therapy (126), but the total number of patients included in these trials was low (334 patients with CD and 67 with UC) and the follow-up period not very long (ranged from 10 months to 2 years). In the single study of UC patients, there were not significant differences between both strategies. However, a recent meta-analysis of these trials shows a significantly higher relapse rate after stopping immunomodulators compared to ongoing therapy $(\mathrm{RR}=1.85,95 \% \mathrm{CI}: 1.44-2.38, P<0.001$, without between-study heterogeneity). In addition, at least three observational studies have analyzed this item. Relapse rates were also higher after withdrawal TP monotherapy (126). It should be noted that many of the studies on TP withdrawal are prior to biological era when alternatives were almost non-existent. In short, although evidence suggests that the relapse rates after TP monotherapy withdrawal is higher, the question that arises is whether it compensates with the long-term toxicity that they can cause in some patients. The most feared adverse event of TP is the occurrence of a lymphoma. The absolute risk is extremely low, but the risk at 2.5-fold and its result is devastating (73). Moreover, there are other risks associated with TP use undoubtedly more common as non-melanoma skin cancers. Interestingly, the risk seems to be proportional to duration of use and decreases on cessation of TP (127). Therefore, a balance of risk-benefit must be carried out individually with each patient, especially since there are other alternatives that are safer in the long-term and more effective, although more expensive. It is important not to forget that recent reports suggest that the risk of lymphoma is comparable for TP and anti-TNF drugs. Embarking on TP treatment is a long journey and clinicians should discuss with patients and decided on a case-by-case basis. If there is one undoubted thing, it is that regular monitoring should be provided to both, in patients continuing TP in the long term and in patients after TP withdrawal.

\section{Authors Comments}

Sometimes it is difficult to interpret the available evidence and to apply it to a specific patient. IBD specialists have been using TP for over 50 years and scientific evidence have demonstrated TP efficacy and effectiveness in the maintenance treatment of both $\mathrm{CD}$ and UC. In fact, population-based long-term observational studies (118) suggest that many patients may benefit from these drugs. However, TP are applicable only in a proportion of patients, because around a $25 \%$ of them have a limiting toxicity that prevents their use. Furthermore, they are only effective in a variable proportion of those who tolerate them. In fact, after a while only a small proportion of the patients, in whom they have been used, continue to be treated with TP. In addition, the risk of toxicity is real and potentially serious, including the possibility of hematological and cutaneous neoplasms. This risk does not disappear over time, and it can affect especially patients over 60 years of age, which in the immediate future will be a very important proportion in IBD patients (128). On the other hand, we have more and more alternatives, that although they are more expensive, present fewer risks than TP. Therefore, although there is still a group of patients in which TP monotherapy is a good option, it seems that TP role is going to become more and more limited, especially if the price of the alternatives decreases.

\section{Combination Therapy (TP Plus Biologics) Evidence}

Post hoc analysis of initial registration trials did not show differences in outcomes stratified by baseline TP treatment. However, in 2010 was published the SONIC trial which included 508 patients naive to both anti-TNF drugs and TP with moderate to severe CD. Results of this trial showed the superiority of combination treatment (TP plus infliximab) compared to infliximab or AZA monotherapy in achieving steroid free clinical remission (56.8\% vs. 44.4 and 30\%, respectively) and mucosal healing (43.9\% vs. 30 and 16.5\%, respectively) at week 26 (9). The rates of adverse events were similar in the three arms and rather, there were significantly lower rates of serious adverse events in those patients that received combination therapy $(\mathrm{RR}=$ 0.56; 95\% CI: 0.32-0.97). Later, the subsequent UC SUCCESS trial employed a similar design than SONIC trial but in naïve UC patients. Results of UC SUCCESS trial were also in favor of combination therapy. Combo-therapy was more effective than either agent alone in inducing clinical remission at week 16 and more effective than AZA monotherapy in reaching mucosal healing $(62.8$ vs. $36.8 \%, p=0.001)$. However, there was no significant difference in the rates of mucosal healing observed with combination therapy vs. infliximab monotherapy (62.8 vs. $54.6 \% ; p=0.295)$ (15). In both trials, AZA cotherapy dramatically reduced the formation of anti-infliximab antibodies (in SONIC 0.9 vs. $14.6 \%$ and in SUCCESS 3 vs. $19 \%)$. SONIC trial also showed an increase in IFX median trough concentrations at week 30 in the combination arm (3.5 
vs. $1.6 \mathrm{micgr} / \mathrm{ml}, p<0.001)$. Conversely, for adalimumab and azathioprine, the DIAMOND trial (only 176 patients with CD) showed rates of clinical remission similar between monotherapy and combination therapy and although the rate of mucosa healing at 26 weeks was superior in combo group, this benefit was not sustained at 1 year (129). Of note, the dose of AZA used in this trial was lower than the usual dose used in $\mathrm{CD}$ patients (25-100 mg/day instead of 2-2.5 mg/kg/day).

Based on pharmacokinetic data of these trials the hypothesis emerged that infliximab is more immunogenic than adalimumab and the addition of immunosuppressive therapy confers more benefit what was reflected as higher drugs level. This hypothesis was supported by the prospective observational UK PANTS study that showed formation of anti-drug antibody was more frequent with infliximab than with adalimumab and was decreased by combination therapy (immunomodulator drug and anti-TNF) (130). Curiously, although the absolute risk of anti-drug antibody was lower with adalimumab, the relative risk reduction with the concomitant use of immunosuppression was similar for both anti-TNF drugs. Combination therapy has also been shown to raise adalimumab levels, which itself is associated with higher rates of clinical and endoscopic remission. Notably, last year (2020) was published the work of Targownik and colleagues that included 11,244 Canadian patients and used data from four population level health care databases (131). Authors showed that use of a concomitant immunomodulator (TP or methotrexate) at the time of anti-TNF initiation (infliximab or adalimumab) was associated with significantly reduction in the likelihood of treatment failure. The choice of immunomodulator did not show a significant effect in CD, but better outcomes were seen with AZA than methotrexate in UC. This study supports that benefits of combination therapy seen in RCT seem to extend to the real-world setting. It also supports the idea that adding an immunomodulator in adalimumab initiation can improve clinical outcome in the medium and long term.

Another commonly encountered scenario in clinical practice is patients who have failed or have had an inadequate response to TP and in whom anti-TNF therapy is started. No RCT has directly compared whether in such cases TP maintenance in combination with the anti-TNF would carry additional benefits in terms of efficacy. A post-hoc analysis of RCTs has shown no added benefit (132). However, immunogenicity should be considered and, in the absence of direct evidence, an individualized approach should be considered.

A new role of TP may be in case of switching anti-TNF. The addition of a TP is an effective method of managing secondary loss of response. A large retrospective study (2017) showed that the addition of an immunomodulator resulted in disappearance of antidrug antibody in $77 \%$ of patients with a subsequent increased of drug concentration and recapture of clinical response (133). Current reactive therapeutic drug monitoringbased algorithms propose that patients with secondary loss of response to anti-TNF with high titer of antidrug antibody should switch to another anti-TNF agent (134). Current evidence shows that these patients have more risk of developing antibody and secondary loss of response to a subsequent anti-TNF $(135,136)$. This effect seems to be able to be mitigated by the addition of a TP as demonstrated Robblin et al. in their RCT (included 90 patients with immune-mediated loss of response to a first anti-TNF in monotherapy) (137).

\section{Authors Comments}

Evidence shows that combination therapy (TP plus anti-TNF) is superior to monotherapy in treating naive $\mathrm{CD}$ and $\mathrm{UC}$ patients, mainly due to the effect of TP on immunogenicity but also partly due to an additive immunosuppressive effect. However, before starting combination therapy, a patientstratified risk of combination therapy-related serious adverse events (special attention to the risk of lymphomas and cutaneous neoplasms with long-term therapies and infections) must be done and a regular monitoring should be provided to these patients. Emerging data suggest that an "optimize anti-TNF monotherapy" using proactive monitoring drug levels to ensure adequate circulating anti-TNF concentrations is associated with higher rates of clinical and endoscopic remission $(138,139)$. This strategy may obviate in the future the need for combination therapy, but a pragmatic trial comparing both strategies has not yet taken place. In any way, in patients in whom monotherapy is chosen, we think that a proactive drug monitoring strategy is advisable. Moreover, testing patients for HLA-DQA1 * 05, which according to recent evidence is associated with an increased risk of development of antibodies against anti-TNF drug, might help physicians decide if patients should be treated with anti-TNF alone or combination therapy (140).

\section{Maintenance After Combination Therapy}

When a patient starts combined treatment there is always a concern about how long the patients should take both treatments. Current clinical guidelines suggest maintenance with the same biologic agent in monotherapy after achieving remission with combination therapy (anti-TNF plus TP) (3, 123). There are conflicting data as to whether continuing TP beyond a certain time provides additional clinical benefit. One study has shown that, in most cases, immunization occurs during the first 12 months of anti-TNF, suggesting that to lengthen the combo-therapy further in many patients may be no necessary (141). A recent meta-analysis including a total of 186 patients with IBD in remission on combination therapy with TP plus anti-TNF (infliximab or adalimumab) analyzed the relapse rate after TP stopping (126). No statistically significant difference was observed between the groups $(\mathrm{RR}=$ 1.30, 95\% CI: 0.81-2.08, $\left.p=0.269 ; I^{2}=0.0 \%, p=0.641\right)$. Van Assche et al. suggested that AZA can be withdrawn after 6 months of remission on combination infliximab/AZA but many patients were on AZA for $>6$ months prior to AZA withdrawal and continuation of combination therapy was associated with lower levels of serum $C$ reactive protein and higher infliximab trough levels (142). In the study of Roblin et al., three strategies were compared: continuing with both treatments, stopping TP and decreasing TP dose (90). There were no clinical significantly differences between the strategies, but authors concluded that reducing the dose of TP was associated globally (considering levels of infliximab, antidrug antibodies and unfavorable evolution) with a better outcome 
than treatment stopping. In combination therapy, a reduced dose of TP may reduce the production of neutralizing antiTNF antibodies, thereby providing a lower chance of developing adverse events. Although TP withdrawal from combination regimen carries a higher risk of anti-drug antibody formation, their effect on clinical outcomes may take longer than a year to become apparent. Meta-analysis of nine studies on adalimumab by Chalhoub et al. (after data included were reanalyzed) did not reveal any differences in maintenance clinical remission $(\mathrm{RR}=1.01,95 \% \mathrm{CI}: 0.91-1.13)$ between combo and monotherapy $(3,143)$. In the ADHERE cohort, an open label extension study of patients included in CHARM study on adalimumab, the rates of clinical remission were similar in patients with and without concomitant immunomodulators at baseline after 3 year of follow up (144). In addition, several observational studies have investigated the risk of relapse in IBD patients who received combination treatment followed by discontinuation of immunomodulator. Two French retrospective observational studies have documented fewer flares, fewer perianal complications and fewer switching with combination therapy for $>2$ years $(145,146)$. Two studies of CD and one of UC reported that a shorter duration of combo-treatment was associated with an increased risk of treatment failure after withdrawal of TP. The thresholds were 27, 6 and 9 months, respectively $(145,147,148)$. Another recent observational study also shows that long combo-therapy ( $>12$ months) was not more efficacious than short combination (149).

\section{Authors Comments}

TP withdrawal from combination with biologics after clinical remission remains a preferred approach of long-term treatment to avoid toxicity, but balancing between adverse drug effects and disease progression is unavoidable in patients with severe

\section{REFERENCES}

1. Ng SC, Shi HY, Hamidi N, Underwood FE, Tang W, Benchimol EI, et al. Worldwide incidence and prevalence of inflammatory bowel disease in the 21st century: a systematic review of population-based studies. Lancet. (2017) 390:2769-78. doi: 10.1016/S0140-6736(17)32448-0

2. Harbord M, Eliakim R, Bettenworth D, Karmiris K, Katsanos K, Kopylov U, et al. Third european evidence-based consensus on diagnosis and management of ulcerative colitis. Part 2: current management. J Crohn's Colitis. (2017) 11:769-84. doi: 10.1093/ecco-jcc/ jjx009

3. Torres J, Bonovas S, Doherty G, Kucharzik T, Gisbert JP, Raine T, et al. ECCO guidelines on therapeutics in Crohn's disease: medical treatment. J Crohns Colitis. (2020) 14:4-22. doi: 10.1093/ecco-jcc/jjz180

4. de Boer NKH, Thiopurine Working Group. Thiopurine therapy in inflammatory bowel diseases: making new friends should not mean losing old ones. Gastroenterology. (2019) 156:11-4. doi: 10.1053/j.gastro.2018.11.039

5. Bermejo F, Aguas M, Chaparro M, Domènech E, Echarri A, García-Planella E, et al. Recommendations of the Spanish Working Group on Crohn's Disease and Ulcerative Colitis (GETECCU) on the use of thiopurines in inflammatory bowel disease. Gastroenterol Hepatol. (2018) 41:20521. doi: 10.1016/j.gastre.2018.03.002

6. Lamb CA, Kennedy NA, Raine T, Hendy PA, Smith PJ, Limdi JK, et al. British Society of Gastroenterology consensus guidelines on the management inflammation and complications. In severe IBD, advantages of combination therapy can outweigh the risk of lymphoma and severe infection, but in patients with mild/moderate IBD, the risk/benefit ratio is clearly less favorable. Predictive factors of relapse and evidence of deep remission should be included in the risk/benefit analysis prior to therapy withdrawal. The need for a RCT to facilitate decision making about the exact timing and optimal group of patients to discontinue therapy is clear. Recently, SPARE trial, that addresses this issue, has been completed and its results will be known soon.

\section{CONCLUSIONS}

Thiopurines are still useful for maintenance of remission in steroid-dependence, prevent post-surgical relapse and improve the outcomes of biologic therapy. The key is to select patients properly based on personal characteristics and the course of the disease. Moreover, as explained above, many strategies are available to improve the efficacy of these drugs and to prevent adverse events.

\section{AUTHOR CONTRIBUTIONS}

FG conceived the idea of the review, coordinated, supervised, and edited the manuscript. CG-P and VL performed the literature review and wrote the manuscript. All authors contributed to the article and approved the submitted version.

\section{FUNDING}

This work was supported by the Institute for Health Research Aragón, IIS Aragón. of inflammatory bowel disease in adults. Gut. (2019) 68(Suppl. 3):s1106. doi: 10.1136/gutjnl-2019-318484

7. Hanauer SB, Sandborn WJ, Lichtenstein GR. Evolving considerations for thiopurine therapy for inflammatory Bowel diseases-a clinical practice update: commentary. Gastroenterology. (2019) 156:36-42. doi: 10.1053/j.gastro.2018.08.043

8. Panés J, López-SanRomán A, Bermejo F, García-Sánchez V, Esteve M, Torres $\mathrm{Y}$, et al. Early azathioprine therapy is no more effective than placebo for newly diagnosed Crohn's disease. Gastroenterology. (2013) 145:76674.e1. doi: 10.1053/j.gastro.2013.06.009

9. Colombel JF, Sandborn WJ, Reinisch W, Mantzaris GJ, Kornbluth A, Rachmilewitz D, et al. Infliximab, azathioprine, or combination therapy for Crohn's disease. N Engl J Med. (2010) 362:138395. doi: 10.1056/NEJMoa0904492

10. Axelrad JE, Roy A, Lawlor G, Korelitz B, Lichtiger S. Thiopurines and inflammatory bowel disease: current evidence and a historical perspective. World J Gastroenterol. (2016) 22:10103-17. doi: 10.3748/wjg.v22.i46.10103

11. Chande N, Patton PH, Tsoulis DJ, Thomas BS, MacDonald JK. Azathioprine or 6-mercaptopurine for maintenance of remission in Crohn's disease. Cochrane database Syst Rev. (2015) 30:CD000067. doi: 10.1002/14651858.CD000067.pub3

12. Timmer A, Patton PH, Chande N, McDonald JWD, MacDonald JK. Azathioprine and 6-mercaptopurine for maintenance of remission in ulcerative colitis. Cochrane database Syst Rev. (2016) 18:CD000478. doi: 10.1002/14651858.CD000478.pub4 
13. López-Sanromán A, Vera-Mendoza I, Domènech E, Taxonera C, Vega Ruiz $\mathrm{V}$, Marín-Jiménez I, et al. Adalimumab vs azathioprine in the prevention of postoperative Crohn's disease recurrence. A GETECCU Randomised Trial. J Crohns Colitis. (2017) 11:1293-301. doi: 10.1093/ecco-jcc/jjx051

14. De Cruz P, Kamm MA, Hamilton AL, Ritchie KJ, Krejany EO, Gorelik A, et al. Efficacy of thiopurines and adalimumab in preventing Crohn's disease recurrence in high-risk patients - a POCER study analysis. Aliment Pharmacol Ther. (2015) 42:867-79. doi: 10.1111/apt.13353

15. Panaccione R, Ghosh S, Middleton S, Márquez JR, Scott BB, Flint L, et al. Combination therapy with infliximab and azathioprine is superior to monotherapy with either agent in ulcerative colitis. Gastroenterology. (2014) 146:392-400.e3. doi: 10.1053/j.gastro.2013.10.052

16. Chaparro M, Ordás I, Cabré E, Garcia-Sanchez V, Bastida G, Peñalva M, et al. Safety of thiopurine therapy in inflammatory bowel disease: longterm follow-up study of 3931 patients. Inflamm Bowel Dis. (2013) 19:140410. doi: 10.1097/MIB.0b013e318281f28f

17. van Gennep S, Konté K, Meijer B, Heymans MW, D’Haens GR, Löwenberg $\mathrm{M}$, et al. Systematic review with meta-analysis: risk factors for thiopurineinduced leukopenia in IBD. Aliment Pharmacol Ther. (2019) 50:484506. doi: 10.1111/apt.15403

18. Gisbert JP, Gomollón F. Thiopurine-induced myelotoxicity in patients with inflammatory bowel disease: a review. Am J Gastroenterol. (2008) 103:1783800. doi: 10.1111/j.1572-0241.2008.01848.x

19. Fries W, Cottone M, Cascio A. Systematic review: macrophage activation syndrome in inflammatory bowel disease. Aliment Pharmacol Ther. (2013) 37:1033-45. doi: 10.1111/apt.12305

20. Teich N, Mohl W, Bokemeyer B, Bündgens B, Büning J, Miehlke S, et al. Azathioprine-induced acute pancreatitis in patients with inflammatory Bowel diseases-a prospective study on incidence and severity. J Crohns Colitis. (2016) 10:61-8. doi: 10.1093/ecco-jcc/jjv188

21. Shaye OA, Yadegari M, Abreu MT, Poordad F, Simon K, Martin P, et al. Hepatotoxicity of 6-Mercaptopurine (6-MP) and Azathioprine (AZA) in Adult IBD patients. Am J Gastroenterol. (2007) 102:248894. doi: 10.1111/j.1572-0241.2007.01515.x

22. Sýkora J, Pomahačová R, Kreslová $M$, Cvalínová $D$, Štych $P$, Schwarz J. Current global trends in the incidence of pediatriconset inflammatory bowel disease. World J Gastroenterol. (2018) 24:2741-63. doi: 10.3748/wjg.v24.i25.2741

23. Pigneur B, Seksik P, Viola S, Viala J, Beaugerie L, Girardet J-P, et al. Natural history of Crohn's disease: comparison between childhood- and adult-onset disease. Inflamm Bowel Dis. (2010) 16:953-61. doi: 10.1002/ibd.21152

24. Adamina M, Bonovas S, Raine T, Spinelli A, Warusavitarne J, Armuzzi A, et al. ECCO guidelines on therapeutics in Crohn's disease: surgical treatment. J Crohns Colitis. (2020) 14:155-68. doi: 10.1093/ecco-jcc/jjz187

25. Windsor JW, Kaplan GG. Evolving epidemiology of IBD. Curr Gastroenterol Rep. (2019) 21:40. doi: 10.1007/s11894-019-0705-6

26. Kuenzig ME, Benchimol EI, Lee L, Targownik LE, Singh H, Kaplan GG, et al. The impact of inflammatory Bowel Disease in Canada 2018: direct costs and health services utilization. JCan Assoc Gastroenterol. (2019) 2(Suppl_1):S1733. doi: 10.1093/jcag/gwy055

27. Biemans VBC, Savelkoul E, Gabriëls RY, Simsek M, Dijkstra G, Pierik MJ, et al. A comparative analysis of tioguanine versus low-dose thiopurines combined with allopurinol in inflammatory bowel disease patients. Aliment Pharmacol Ther. (2020) 51:1076-86. doi: 10.1111/apt.15730

28. Blaker PA, Arenas-Hernandez M, Marinaki AM, Sanderson JD. The pharmacogenetic basis of individual variation in thiopurine metabolism. Per Med. (2012) 9:707-25. doi: 10.2217/pme.12.85

29. Tiede I, Fritz G, Strand S, Poppe D, Dvorsky R, Strand D, et al. CD28dependent Racl activation is the molecular target of azathioprine in primary human CD4+ T lymphocytes. J Clin Invest. (2003) 111:113345. doi: $10.1172 /$ JCI16432

30. Karran P, Attard N. Thiopurines in current medical practice: molecular mechanisms and contributions to therapy-related cancer. Nat Rev Cancer. (2008) 8:24-36. doi: 10.1038/nrc2292

31. Moon W, Loftus E V. Review article: recent advances in pharmacogenetics and pharmacokinetics for safe and effective thiopurine therapy in inflammatory bowel disease. Aliment Pharmacol Ther. (2016) 43:86383. doi: 10.1111/apt.13559
32. Relling M V., Schwab M, Whirl-Carrillo M, Suarez-Kurtz G, Pui C, Stein CM, et al. Clinical pharmacogenetics implementation consortium guideline for thiopurine dosing based on TPMT and NUDT 15 genotypes: 2018 update. Clin Pharmacol Ther. (2019) 105:1095-105. doi: 10.1002/cpt.1304

33. Bangma A, Voskuil MD, Uniken Venema WTC, Brugge H, Hu S, Lanting P, et al. Predicted efficacy of a pharmacogenetic passport for inflammatory bowel disease. Aliment Pharmacol Ther. (2020) 51:110515. doi: 10.1111/apt.15762

34. Lim SZ, Chua EW. Revisiting the role of thiopurines in inflammatory Bowel disease through pharmacogenomics and use of novel methods for therapeutic drug monitoring. Front Pharmacol. (2018) 9:1107. doi: 10.3389/fphar.2018.01107

35. Relling M V, Gardner EE, Sandborn WJ, Schmiegelow K, Pui C-H, Yee SW, et al. Clinical pharmacogenetics implementation consortium guidelines for thiopurine methyltransferase genotype and thiopurine dosing. Clin Pharmacol Ther. (2011) 89:387-91. doi: 10.1038/clpt.2010.320

36. Krynetski EY, Tai HL, Yates CR, Fessing MY, Loennechen T, Schuetz JD, et al. Genetic polymorphism of thiopurine S-methyltransferase: clinical importance and molecular mechanisms. Pharmacogenetics. (1996) 6:27990. doi: 10.1097/00008571-199608000-00001

37. Coenen MJH, de Jong DJ, van Marrewijk CJ, Derijks LJJ, Vermeulen $\mathrm{SH}$, Wong DR, et al. Identification of patients with variants in TPMT and dose reduction reduces hematologic events during thiopurine treatment of inflammatory Bowel disease. Gastroenterology. (2015) 149:90717.e7. doi: 10.1053/j.gastro.2015.06.002

38. Lennard L. Implementation of TPMT testing. Br J Clin Pharmacol. (2014) 77:704-14. doi: 10.1111/bcp.12226

39. Hindorf U, Appell ML. Genotyping should be considered the primary choice for pre-treatment evaluation of thiopurine methyltransferase function. J Crohns Colitis. (2012) 6:655-9. doi: 10.1016/j.crohns.2011.11.014

40. Newman WG, Payne K, Tricker K, Roberts SA, Fargher E, Pushpakom $\mathrm{S}$, et al. A pragmatic randomized controlled trial of thiopurine methyltransferase genotyping prior to azathioprine treatment: the TARGET study. Pharmacogenomics. (2011) 12:815-26. doi: 10.2217/pgs.11.32

41. Dewit O, Moreels T, Baert F, Peeters H, Reenaers C, de Vos M, et al. Limitations of extensive TPMT genotyping in the management of azathioprine-induced myelosuppression in IBD patients. Clin Biochem. (2011) 44:1062-6. doi: 10.1016/j.clinbiochem.2011.06.079

42. Vande Casteele N, Herfarth H, Katz J, Falck-Ytter Y, Singh S. American gastroenterological association institute technical review on the role of therapeutic drug monitoring in the management of inflammatory Bowel diseases. Gastroenterology. (2017) 153:835-57.e6. doi: 10.1053/j.gastro.2017.07.031

43. Feuerstein JD, Nguyen GC, Kupfer SS, Falck-Ytter Y, Singh S, American Gastroenterological Association Institute Clinical Guidelines Committee. American Gastroenterological Association Institute Guideline on Therapeutic Drug Monitoring in Inflammatory Bowel disease. Gastroenterology. (2017) 153:827-34. doi: 10.1053/j.gastro.2017.07.032

44. Sluiter RL, Van Marrewijk C, De Jong D, Scheffer H, Guchelaar H-J, Derijks $\mathrm{L}$, et al. Genotype-guided thiopurine dosing does not lead to additional costs in patients with inflammatory bowel Disease. J Crohns Colitis. (2019) 13:838-45. doi: 10.1093/ecco-jcc/jjz009

45. Kim JH, Cheon JH, Hong SS, Eun CS, Byeon J-S, Hong SY, et al. Influences of thiopurine methyltransferase genotype and activity on thiopurine-induced leukopenia in Korean patients with inflammatory Bowel disease. J Clin Gastroenterol. (2010) 44:e242-8. doi: 10.1097/MCG.0b013e3181d6baf5

46. Jung YS, Cheon JH, Park JJ, Moon CM, Kim ES, Lee JH, et al. Correlation of genotypes for thiopurine methyltransferase and inosine triphosphate pyrophosphatase with long-term clinical outcomes in Korean patients with inflammatory bowel diseases during treatment with thiopurine drugs. J Hum Genet. (2010) 55:121-3. doi: 10.1038/jhg.20 09.125

47. Collie-Duguid ES, Pritchard SC, Powrie RH, Sludden J, Collier DA, Li $\mathrm{T}$, et al. The frequency and distribution of thiopurine methyltransferase alleles in Caucasian and Asian populations. Pharmacogenetics. (1999) 9:3742. doi: 10.1097/00008571-199902000-00006

48. Jun JB, Cho DY, Kang C, Bae SC. Thiopurine S-methyltransferase polymorphisms and the relationship between the mutant alleles and the 
adverse effects in systemic lupus erythematosus patients taking azathioprine. Clin Exp Rheumatol. (2005) 23:873-6.

49. Moriyama T, Nishii R, Perez-Andreu V, Yang W, Klussmann FA, Zhao $\mathrm{X}$, et al. NUDT15 polymorphisms alter thiopurine metabolism and hematopoietic toxicity. Nat Genet. (2016) 48:367-73. doi: 10.1038/ng.3508

50. Walker GJ, Harrison JW, Heap GA, Voskuil MD, Andersen V, Anderson CA, et al. Association of genetic variants in NUDT15 with thiopurineinduced myelosuppression in patients with inflammatory Bowel disease. JAMA. (2019) 321:773-85. doi: 10.1001/jama.2019.0709

51. Wang H-H, He Y, Wang H-X, Liao C-L, Peng Y, Tao L-J, et al. Comparison of TPMT and NUDT15 polymorphisms in Chinese patients with inflammatory bowel disease. World J Gastroenterol. (2018) 24:9418. doi: 10.3748/wjg.v24.i8.941

52. Moriyama T, Nishii R, Lin T-N, Kihira K, Toyoda H, Jacob N, et al. The effects of inherited NUDT15 polymorphisms on thiopurine active metabolites in Japanese children with acute lymphoblastic leukemia. Pharmacogenet Genomics. (2017) 27:236-9. doi: 10.1097/FPC.0000000000000282

53. Yang S-K, Hong M, Baek J, Choi H, Zhao W, Jung Y, et al. A common missense variant in NUDT15 confers susceptibility to thiopurine-induced leukopenia. Nat Genet. (2014) 46:1017-20. doi: 10.1038/ng.3060

54. Kakuta Y, Kinouchi Y, Shimosegawa T. Pharmacogenetics of thiopurines for inflammatory bowel disease in East Asia: prospects for clinical application of NUDT15 genotyping. J Gastroenterol. (2018) 53:17280. doi: 10.1007/s00535-017-1416-0

55. Yang JJ, Landier W, Yang W, Liu C, Hageman L, Cheng C, et al. Inherited NUDT15 variant is a genetic determinant of mercaptopurine intolerance in children with acute lymphoblastic leukemia. J Clin Oncol. (2015) 33:123542. doi: 10.1200/JCO.2014.59.4671

56. Chang JY, Park SJ, Jung ES, Jung S-A, Moon CM, Chun J, et al. Genotypebased treatment with thiopurine reduces incidence of myelosuppression in patients with inflammatory Bowel diseases. Clin Gastroenterol Hepatol. (2020) 18:2010-18.e2. doi: 10.1016/j.cgh.2019.08.034

57. Kim HS, Cheon JH, Jung ES, Park J, Aum S, Park SJ, et al. A coding variant in FTO confers susceptibility to thiopurine-induced leukopenia in East Asian patients with IBD. Gut. (2017) 66:1926-35. doi: 10.1136/gutjnl-2016-311921

58. Chen S, Tan WZ, Sutiman N, Lim C, Lee SS, Leong WF, et al. An intronic FTO variant rs16952570 confers protection against thiopurine-induced myelotoxicities in multiethnic Asian IBD patients. Pharmacogenomics J. (2020) 20:505-15. doi: 10.1038/s41397-019-0126-9

59. Heap GA, Weedon MN, Bewshea CM, Singh A, Chen M, Satchwell JB, et al. HLA-DQA1-HLA-DRB1 variants confer susceptibility to pancreatitis induced by thiopurine immunosuppressants. Nat Genet. (2014) 46:11314. doi: $10.1038 / \mathrm{ng} .3093$

60. Wilson A, Jansen LE, Rose R V., Gregor JC, Ponich T, Chande N, et al. HLADQA1-HLA-DRB1 polymorphism is a major predictor of azathioprineinduced pancreatitis in patients with inflammatory bowel disease. Aliment Pharmacol Ther. (2018) 47:615-20. doi: 10.1111/apt.14483

61. Koifman E, Karban A, Mazor Y, Chermesh I, Waterman M, Almog R, et al. Thiopurine effectiveness in patients with Crohn's disease. Inflamm Bowel Dis. (2013) 19:1639-44. doi: 10.1097/MIB.0b013e31828828d3

62. Van Dieren JM, Hansen BE, Kuipers EJ, Nieuwenhuis EES, Van Der Woude CJ. Meta-analysis: inosine triphosphate pyrophosphatase polymorphisms and thiopurine toxicity in the treatment of inflammatory bowel disease. Aliment Pharmacol Ther. (2007) 26:643-52. doi: 10.1111/j.1365-2036.2007.03412.x

63. Shipkova M, Franz J, Abe M, Klett C, Wieland E, Andus T. Association between adverse effects under azathioprine therapy and inosine triphosphate pyrophosphatase activity in patients with chronic inflammatory Bowel disease. ther drug monit. (2011) 33:321-8. doi: 10.1097/FTD.0b013e31821a7c34

64. Everhov ÅH, Halfvarson J, Myrelid P, Sachs MC, Nordenvall C, Söderling $\mathrm{J}$, et al. Incidence and treatment of patients diagnosed with inflammatory bowel diseases at 60 years or older in Sweden. Gastroenterology. (2018) 154:518-28.e15. doi: 10.1053/j.gastro.2017.10.034

65. Calafat $\mathrm{M}$, Mañosa $\mathrm{M}$, Cañete $\mathrm{F}$, Ricart $\mathrm{E}$, Iglesias $\mathrm{E}$, Calvo $\mathrm{M}$, et al. Increased risk of thiopurine-related adverse events in elderly patients with IBD. Aliment Pharmacol Ther. (2019) 50:780-8. doi: 10.1111/apt.15458
66. Parian A, Ha CY. Older age and steroid use are associated with increasing polypharmacy and potential medication interactions among patients with inflammatory bowel disease. Inflamm Bowel Dis. (2015) 21:1392-400. doi: 10.1097/MIB.0000000000000391

67. Lobatón T, Ferrante M, Rutgeerts P, Ballet V, Van Assche G, Vermeire S. Efficacy and safety of anti-TNF therapy in elderly patients with inflammatory bowel disease. Aliment Pharmacol Ther. (2015) 42:44151. doi: 10.1111/apt.13294

68. Bourrier A, Carrat F, Colombel J-F, Bouvier A-M, Abitbol V, Marteau P, et al. Excess risk of urinary tract cancers in patients receiving thiopurines for inflammatory bowel disease: a prospective observational cohort study. Aliment Pharmacol Ther. (2016) 43:252-61. doi: 10.1111/apt.13466

69. de Francisco R, Castaño-García A, Martínez-González S, Pérez-Martínez I, González-Huerta AJ, Morais LR, et al. Impact of Epstein-Barr virus serological status on clinical outcomes in adult patients with inflammatory bowel disease. Aliment Pharmacol Ther. (2018) 48:72330. doi: 10.1111/apt.14933

70. van Langenberg DR, Morrison G, Foley A, Buttigieg RJ, Gibson PR. Cytomegalovirus disease, haemophagocytic syndrome, immunosuppression in patients with IBD: 'A cocktail best avoided, not stirred.' J Crohns Colitis. (2011) 5:469-72. doi: 10.1016/j.crohns.2011.04.010

71. Voet MP, Calon TG, Hendriks MM, Schreuder RM. Severe complication of thiopurine treatment in a young woman with Crohn's disease. Eur J Case Reports Intern Med. (2021) 8:002350. doi: 10.12890/2021_002350

72. Wisniewski A, Kirchgesner J, Seksik P, Landman C, Bourrier A, NionLarmurier I, et al. Increased incidence of systemic serious viral infections in patients with inflammatory bowel disease associates with active disease and use of thiopurines. United Eur Gastroenterol J. (2020) 8:30313. doi: $10.1177 / 2050640619889763$

73. Chupin A, Perduca V, Meyer A, Bellanger C, Carbonnel F, Dong C. Systematic review with meta-analysis: comparative risk of lymphoma with anti-tumour necrosis factor agents and/or thiopurines in patients with inflammatory bowel disease. Aliment Pharmacol Ther. (2020) 52:128997. doi: 10.1111/apt.16050

74. Levhar N, Ungar B, Kopylov U, Fudim E, Yavzori M, Picard O, et al. Propagation of EBV-driven lymphomatous transformation of peripheral blood B cells by immunomodulators and biologics used in the treatment of inflammatory Bowel Disease. Inflamm Bowel Dis. (2020) 26:13309. doi: 10.1093/ibd/izaa065

75. Beaugerie L, Brousse N, Bouvier AM, Colombel JF, Lémann M, Cosnes J, et al. Lymphoproliferative disorders in patients receiving thiopurines for inflammatory bowel disease: a prospective observational cohort study. Lancet. (2009) 374:1617-25. doi: 10.1016/S0140-6736(09)61302-7

76. Khan N, Patel D, Trivedi C, Kavani H, Pernes T, Medvedeva E, et al. Incidence of acute myeloid leukemia and myelodysplastic syndrome in patients with inflammatory Bowel disease and the impact of thiopurines on their risk. Am J Gastroenterol. (2020) 8:443-68. doi: 10.14309/ajg.0000000000001058

77. Rahier JF, Magro F, Abreu C, Armuzzi A, Ben-Horin S, Chowers Y, et al. Second European evidence-based consensus on the prevention, diagnosis and management of opportunistic infections in inflammatory bowel disease. J Crohns Colitis. (2014) 8:443-68. doi: 10.1016/j.crohns.2013.12.013

78. Sheng YH, Giri R, Davies J, Schreiber V, Alabbas S, Movva R, et al. A nucleotide analog prevents colitis-associated cancer via beta-catenin independently of inflammation and autophagy. Cell Mol Gastroenterol Hepatol. (2021) 11:33-53. doi: 10.1016/j.jcmgh.2020.05.012

79. Coulthard SA, Berry P, McGarrity S, McLaughlin S, Ansari A, Redfern CPF. Azathioprine with allopurinol: lower deoxythioguanosine in DNA and transcriptome changes indicate mechanistic differences to azathioprine alone. Inflamm Bowel Dis. (2017) 23:946-55. doi: 10.1097/MIB.0000000000001131

80. Wall GC, Muktar H, Effken C, Mahajan PB. Addition of allopurinol for altering thiopurine metabolism to optimize therapy in patients with inflammatory Bowel disease. Pharmacotherapy. (2018) 38:25970. doi: 10.1002/phar.2067

81. Smith MA, Blaker P, Marinaki AM, Anderson SH, Irving PM, Sanderson JD. Optimising outcome on thiopurines in inflammatory 
bowel disease by co-prescription of allopurinol. J Crohns Colitis. (2012) 6:905-12. doi: 10.1016/j.crohns.2012.02.007

82. Sparrow MP, Hande SA, Friedman S, Lim WC, Reddy SI, Cao $\mathrm{D}$, et al. Allopurinol safely and effectively optimizes tioguanine metabolites in inflammatory bowel disease patients not responding to azathioprine and mercaptopurine. Aliment Pharmacol Ther. (2005) 22:441-6. doi: 10.1111/j.1365-2036.2005.02583.x

83. Friedman AB, Brown SJ, Bampton P, Barclay ML, Chung A, Macrae FA, et al. Randomised clinical trial: efficacy, safety and dosage of adjunctive allopurinol in azathioprine/mercaptopurine nonresponders (AAA Study). Aliment Pharmacol Ther. (2018) 47:1092-102. doi: 10.1111/apt.14571

84. Pavlidis P, Stamoulos P, Abdulrehman A, Kerr P, Bull C, Duley J, et al. Longterm safety and efficacy of low-dose azathioprine and allopurinol cotherapy in inflammatory Bowel disease: a large observational study. Inflamm Bowel Dis. (2016) 22:1639-46. doi: 10.1097/MIB.0000000000000827

85. Sousa P, Estevinho MM, Dias CC, Ministro P, Kopylov U, Danese S, et al. Thiopurines' metabolites and drug toxicity: a meta-analysis. J Clin Med. (2020) 9:2216. doi: 10.3390/jcm9072216

86. Mao R, Guo J, Luber R, Chen B-L, He Y, Zeng Z-R, et al. 6-Thioguanine nucleotide levels are associated with mucosal healing in patients with Crohn's disease. Inflamm Bowel Dis. (2018) 24:2621-7. doi: 10.1093/ibd/izy173

87. Feng R, Guo J, Zhang S-H, Qiu Y, Chen B-L, He Y, et al. Low 6thioguanine nucleotide level: effective in maintaining remission in Chinese patients with Crohn's disease. J Gastroenterol Hepatol. (2019) 34:67985. doi: 10.1111/jgh.14465

88. Mogensen D V, Brynskov J, Ainsworth MA, Nersting J, Schmiegelow K, Steenholdt C. A role for thiopurine metabolites in the synergism between thiopurines and infliximab in inflammatory Bowel disease. J Crohn's Colitis. (2018) 12:298-305. doi: 10.1093/ecco-jcc/jjx149

89. Yarur AJ, Kubiliun MJ, Czul F, Sussman DA, Quintero MA, Jain A, et al. Concentrations of 6-thioguanine nucleotide correlate with trough levels of infliximab in patients with inflammatory bowel disease on combination therapy. Clin Gastroenterol Hepatol. (2015) 13:111824.e3. doi: 10.1016/j.cgh.2014.12.026

90. Roblin X, Boschetti G, Williet N, Nancey S, Marotte H, Berger A, et al. Azathioprine dose reduction in inflammatory bowel disease patients on combination therapy: an open-label, prospective and randomised clinical trial. Aliment Pharmacol Ther. (2017) 46:142-9. doi: 10.1111/apt.14106

91. Goel RM, Blaker P, Mentzer A, Fong SCM, Marinaki AM, Sanderson JD. Optimizing the use of thiopurines in inflammatory bowel disease. Ther Adv Chronic Dis. (2015) 6:138-46. doi: 10.1177/2040622315579063

92. Wong DR, Coenen MJH, Derijks LJJ, Vermeulen SH, van Marrewijk CJ, Klungel $\mathrm{OH}$, et al. Early prediction of thiopurine-induced hepatotoxicity in inflammatory bowel disease. Aliment Pharmacol Ther. (2017) 45:391402. doi: 10.1111/apt.13879

93. Dubinsky MC, Lamothe S, Yang HY, Targan SR, Sinnett D, Théorêt Y, et al. Pharmacogenomics and metabolite measurement for 6-mercaptopurine therapy in inflammatory bowel disease. Gastroenterology. (2000) 118:70513. doi: 10.1016/S0016-5085(00)70140-5

94. Luber RP, Honap S, Cunningham G, Irving PM. Can we predict the toxicity and response to thiopurines in inflammatory Bowel diseases? Front Med. (2019) 6:279. doi: 10.3389/fmed.2019.00279

95. Reinshagen M, Schütz E, Armstrong VW, Behrens C, von Tirpitz C, Stallmach A, et al. 6-thioguanine nucleotide-adapted azathioprine therapy does not lead to higher remission rates than standard therapy in chronic active crohn disease: results from a randomized, controlled, open trial. Clin Chem. (2007) 53:1306-14. doi: 10.1373/clinchem.2007.086215

96. González-Lama Y, Bermejo F, López-Sanromán A, García-Sánchez V, Esteve M, Cabriada JL, et al. Thiopurine methyl-transferase activity and azathioprine metabolite concentrations do not predict clinical outcome in thiopurine-treated inflammatory bowel disease patients. Aliment Pharmacol Ther. (2011) 34:544-54. doi: 10.1111/j.1365-2036.2011.04756.x

97. Sánchez Rodríguez E, Ríos León R, Mesonero Gismero F, Albillos A, LopezSanroman A. Clinical experience of optimising thiopurine use through metabolite measeurement in inflammatory bowel disease. Gastroenterol Hepatol. (2018) 41:629-35. doi: 10.1016/j.gastre.2018.11.027

98. Lee JH, Kim TJ, Kim ER, Hong SN, Chang DK, Choi L-H, et al. Measurements of 6-thioguanine nucleotide levels with TPMT and
NUDT15 genotyping in patients with Crohn's disease. PLoS ONE. (2017) 12:e0188925. doi: 10.1371/journal.pone.0188925

99. Taylor KM, Ward MG, Blaker PA, Sparrow MP. Is there a role for thioguanine therapy in IBD in 2017 and beyond? Expert Rev Gastroenterol Hepatol. (2017) 11:473-86. doi: 10.1080/17474124.2017.1294062

100. Oancea I, Movva R, Das I, Aguirre de Cárcer D, Schreiber V, Yang Y, et al. Colonic microbiota can promote rapid local improvement of murine colitis by thioguanine independently of T lymphocytes and host metabolism. Gut. (2017) 66:59-69. doi: 10.1136/gutjnl-2015-310874

101. Meijer B, Mulder CJ, Peters GJ, van Bodegraven AA, de Boer NK. Efficacy of thioguanine treatment in inflammatory bowel disease: a systematic review. World J Gastroenterol. (2016) 22:9012-21. doi: 10.3748/wjg.v22.i40.9012

102. Simsek M, Deben DS, Horjus CS, Bénard M V, Lissenberg-Witte BI, Buiter HJC, et al. Sustained effectiveness, safety and therapeutic drug monitoring of tioguanine in a cohort of 274 IBD patients intolerant for conventional therapies. Aliment Pharmacol Ther. (2019) 50:54-65. doi: 10.1111/apt.15280

103. Jharap B, Seinen ML, de Boer NKH, van Ginkel JR, Linskens RK, Kneppelhout JC, et al. Thiopurine therapy in inflammatory bowel disease patients: analyses of two 8-year intercept cohorts. Inflamm Bowel Dis. (2010) 16:1541-9. doi: 10.1002/ibd.21221

104. Dubinsky MC, Vasiliauskas EA, Singh H, Abreu MT, Papadakis $\mathrm{KA}$, Tran T, et al. 6-thioguanine can cause serious liver injury in inflammatory bowel disease patients. Gastroenterology. (2003) 125:298-303. doi: 10.1016/S0016-5085(03)00938-7

105. de Boer NKH, Zondervan PE, Gilissen LPL, den Hartog G, Westerveld BD, Derijks LJJ, et al. Absence of nodular regenerative hyperplasia after low-dose 6-thioguanine maintenance therapy in inflammatory bowel disease patients. Dig Liver Dis. (2008) 40:108-13. doi: 10.1016/j.dld.2007.10.013

106. van Asseldonk DP, Jharap B, Kuik DJ, de Boer NKH, Westerveld BD, Russel MGVM, et al. Prolonged thioguanine therapy is well tolerated and safe in the treatment of ulcerative colitis. Dig Liver Dis. (2011) 43:1105. doi: 10.1016/j.dld.2010.07.004

107. Gilissen LPL, Derijks LJJ, Driessen A, Bos LP, Hooymans PM, Stockbrügger RW, et al. Toxicity of 6-thioguanine: no hepatotoxicity in a series of IBD patients treated with long-term, low dose 6-thioguanine. Some evidence for dose or metabolite level dependent effects? Dig Liver Dis. (2007) 39:1569. doi: 10.1016/j.dld.2006.10.007

108. Toksvang LN, Schmidt MS, Arup S, Larsen RH, Frandsen TL, Schmiegelow $\mathrm{K}$, et al. Hepatotoxicity during 6-thioguanine treatment in inflammatory bowel disease and childhood acute lymphoblastic leukaemia: a systematic review. PLoS ONE. (2019) 14:e0212157. doi: 10.1371/journal.pone.0212157

109. van Asseldonk DP, Jharap B, Verheij J, den Hartog G, Westerveld DB, Becx MC, et al. The prevalence of nodular regenerative hyperplasia in inflammatory Bowel disease patients treated with thioguanine is not associated with clinically significant liver disease. Inflamm Bowel Dis. (2016) 22:2112-20. doi: 10.1097/MIB.0000000000000869

110. Summers RW, Switz DM, Sessions JT, Becktel JM, Best WR, Kern F, et al. National Cooperative Crohn's Disease Study: results of drug treatment. Gastroenterology. (1979) $77 \quad$ (4 Pt 2):847-69. doi: 10.1016/0016-5085(79)90385-8

111. Candy S, Wright J, Gerber M, Adams G, Gerig M, Goodman R. A controlled double blind study of azathioprine in the management of Crohn's disease. Gut. (1995) 37:674-8. doi: 10.1136/gut.37.5.674

112. Ewe K, Press AG, Singe CC, Stufler M, Ueberschaer B, Hommel G, et al. Azathioprine combined with prednisolone or monotherapy with prednisolone in active Crohn's disease. Gastroenterology. (1993) 105:36772. doi: 10.1016/0016-5085(93)90709-L

113. Klein M, Binder HJ, Mitchell M, Aaronson R, Spiro H. Treatment of Crohn's disease with azathioprine: a controlled evaluation. Gastroenterology. (1974) 66:916-22. doi: 10.1016/S0016-5085(74)80166-6

114. Present DH, Korelitz BI, Wisch N, Glass JL, Sachar DB, Pasternack BS. Treatment of Crohn's Disease with 6-Mercaptopurine. A longterm, randomized, double-blind study. N Engl J Med. (1980) 302:9817. doi: 10.1056/NEJM198005013021801

115. Reinisch W, Panés J, Lémann $M$, Schreiber S, Feagan B, Schmidt S, et al. A multicenter, randomized, double-blind trial of everolimus versus azathioprine and placebo to maintain steroid-induced remission in patients with moderate-to-severe active Crohn's disease. Am J 
Gastroenterol. (2008) 103:2284-92. doi: 10.1111/j.1572-0241.2008. 02024.x

116. Rhodes J, Beck P, Bainton D, Campbell H. Controlled trial of azathioprine in Crohn's disease. Lancet. (1971) 298:12736. doi: 10.1016/S0140-6736(71)90598-8

117. Willoughby JM, Beckett J, Kumar PJ, Dawson AM. Controlled trial of azathioprine in Crohn's disease. Lancet. (1971) 2:9447. doi: 10.1016/S0140-6736(71)90268-6

118. Stournaras E, Qian W, Pappas A, Hong YY, Shawky R, Raine T, et al. Thiopurine monotherapy is effective in ulcerative colitis but significantly less so in Crohn's disease: long-term outcomes for 11928 patients in the UK inflammatory bowel disease bioresource. Gut. (2021) 70:67786. doi: 10.1136/gutjnl-2019-320185

119. Verstockt B, Boets L, Sabino J, Vermeire S, Ferrante M. Thiopurine monotherapy has a limited place in treatment of patients with mild-to-moderate Crohn's disease. Gut. (2021) 70:1416-8. doi: 10.1136/gutjnl-2020-322646

120. Gjuladin-Hellon T, Iheozor-Ejiofor Z, Gordon M, Akobeng AK. Azathioprine and 6-mercaptopurine for maintenance of surgicallyinduced remission in Crohn's disease. Cochrane Database Syst Rev. (2019) 8:CD010233. doi: 10.1002/14651858.CD010233.pub3

121. Cosnes J, Bourrier A, Laharie D, Nahon S, Bouhnik Y, Carbonnel F, et al. Early administration of azathioprine vs conventional management of Crohn's Disease: a randomized controlled trial. Gastroenterology. (2013) 145:75865.e2; quiz e14-5. doi: 10.1053/j.gastro.2013.04.048

122. Gisbert JP, Linares PM, McNicholl AG, Maté J, Gomollón F. Metaanalysis: the efficacy of azathioprine and mercaptopurine in ulcerative colitis. Aliment Pharmacol Ther. (2009) 30:126-37. doi: 10.1111/j.1365-2036.2009. 04023.x

123. Sicilia B, García-López S, González-Lama Y, Zabana Y, Hinojosa J, Gomollón F. GETECCU 2020 guidelines for the treatment of ulcerative colitis. Developed using the GRADE approach. Gastroenterol Hepatol. (2020) 43(Suppl. 1):1-57. doi: 10.1016/j.gastrohep.2020.07.001

124. Ardizzone S, Maconi G, Russo A, Imbesi V, Colombo E, Bianchi Porro G. Randomised controlled trial of azathioprine and 5-aminosalicylic acid for treatment of steroid dependent ulcerative colitis. Gut. (2006) 55:4753. doi: 10.1136/gut.2005.068809

125. Bojic D, Radojicic Z, Nedeljkovic-Protic M, Al-Ali M, Jewell DP, Travis SPL. Long-term outcome after admission for acute severe ulcerative colitis in Oxford: the 1992-1993 cohort. Inflamm Bowel Dis. (2009) 15:8238. doi: 10.1002/ibd.20843

126. Dohos D, Hanák L, Szakács Z, Kiss S, Párniczky A, Eross B, et al. Systematic review with meta-analysis: the effects of immunomodulator or biological withdrawal from mono- or combination therapy in inflammatory bowel disease. Aliment Pharmacol Ther. (2021) 53:220-33. doi: 10.1111/apt.16182

127. Hagen JW, Pugliano-Mauro MA. Nonmelanoma skin cancer risk in patients with inflammatory Bowel disease undergoing thiopurine therapy: a systematic review of the literature. Dermatologic Surg. (2018) 44:46980. doi: 10.1097/DSS.0000000000001455

128. Kaplan GG, Windsor JW. The four epidemiological stages in the global evolution of inflammatory bowel disease. Nat Rev Gastroenterol Hepatol. (2021) 18:56-66. doi: 10.1038/s41575-020-00360-x

129. Matsumoto T, Motoya S, Watanabe K, Hisamatsu T, Nakase H, Yoshimura $\mathrm{N}$, et al. Adalimumab monotherapy and a combination with azathioprine for Crohn's disease: a prospective, randomized trial. J Crohns Colitis. (2016) 10:1259-66. doi: 10.1093/ecco-jcc/jjw152

130. Kennedy NA, Heap GA, Green HD, Hamilton B, Bewshea C, Walker GJ, et al. Predictors of anti-TNF treatment failure in anti-TNFnaive patients with active luminal Crohn's disease: a prospective, multicentre, cohort study. Lancet Gastroenterol Hepatol. (2019) 4:341-53. doi: 10.1016/S2468-1253(19)30012-3

131. Targownik LE, Benchimol EI, Bernstein CN, Singh H, Tennakoon A, Zubieta AA, et al. Combined biologic and immunomodulatory therapy is superior to monotherapy for decreasing the risk of inflammatory Bowel disease-related complications. J Crohn's Colitis. (2020) 14:135463. doi: 10.1093/ecco-jcc/jjaa050

132. Jones JL, Kaplan GG, Peyrin-Biroulet L, Baidoo L, Devlin S, Melmed GY, et al. Effects of concomitant immunomodulator therapy on efficacy and safety of anti-tumor necrosis factor therapy for Crohn's disease: a metaanalysis of placebo-controlled trials. Clin Gastroenterol Hepatol. (2015) 13:2233-40.e2. doi: 10.1016/j.cgh.2015.06.034

133. Strik AS, van den Brink GR, Ponsioen C, Mathot R, Löwenberg M, D’Haens GR. Suppression of anti-drug antibodies to infliximab or adalimumab with the addition of an immunomodulator in patients with inflammatory bowel disease. Aliment Pharmacol Ther. (2017) 45:1128-34. doi: 10.1111/apt.13994

134. Papamichael K, Vogelzang EH, Lambert J, Wolbink G, Cheifetz AS. Therapeutic drug monitoring with biologic agents in immune mediated inflammatory diseases. Expert Rev Clin Immunol. (2019) 15:837-48. doi: 10.1080/1744666X.2019.1630273

135. Frederiksen MT, Ainsworth MA, Brynskov J, Thomsen OØ, Bendtzen $\mathrm{K}$, Steenholdt C. Antibodies against infliximab are associated with de novo development of antibodies to adalimumab and therapeutic failure in infliximab-to-adalimumab switchers with IBD. Inflamm Bowel Dis. (2014) 20:1714-21. doi: 10.1097/MIB.0000000000000138

136. Roblin X, Vérot C, Paul S, Duru G, Williet N, Boschetti G, et al. Is the pharmacokinetic profile of a first anti-TNF predictive of the clinical outcome and pharmacokinetics of a second anti-TNF? Inflamm Bowel Dis. (2018) 24:2078-85. doi: 10.1093/ibd/izy111

137. Roblin X, Williet N, Boschetti G, Phelip J-M, Del Tedesco E, Berger AE, et al. Addition of azathioprine to the switch of anti-TNF in patients with IBD in clinical relapse with undetectable anti-TNF trough levels and antidrug antibodies: a prospective randomised trial. Gut. (2020) 69:120612. doi: 10.1136/gutjnl-2019-319758

138. Lega S, Phan BL, Rosenthal CJ, Gordon J, Haddad N, Pittman N, et al. Proactively optimized infliximab monotherapy is as effective as combination therapy in IBD. Inflamm Bowel Dis. (2019) 25:13441. doi: $10.1093 /$ ibd/izy203

139. Drobne D, Kurent T, Golob S, Švegl P, Rajar P, HanŽel J, et al. Optimised infliximab monotherapy is as effective as optimised combination therapy, but is associated with higher drug consumption in inflammatory bowel disease. Aliment Pharmacol Ther. (2019) 49:880-9. doi: 10.1111/apt.15179

140. Sazonovs A, Kennedy NA, Moutsianas L, Heap GA, Rice DL, Reppell M, et al. HLA-DQA1*05 carriage associated with development of anti-drug antibodies to infliximab and adalimumab in patients with Crohn's disease. Gastroenterology. (2020) 158:189-99. doi: 10.1053/j.gastro.2019.09.041

141. Ungar B, Chowers Y, Yavzori M, Picard O, Fudim E, Har-Noy O, et al. The temporal evolution of antidrug antibodies in patients with inflammatory bowel disease treated with infliximab. Gut. (2014) 63:125864. doi: 10.1136/gutjnl-2013-305259

142. Van Assche G, Magdelaine-Beuzelin C, D’Haens G, Baert F, Noman $\mathrm{M}$, Vermeire S, et al. Withdrawal of immunosuppression in Crohn's disease treated with scheduled infliximab maintenance: a randomized trial. Gastroenterology. (2008) 134:1861-8. doi: 10.1053/j.gastro.2008. 03.004

143. Chalhoub JM, Rimmani HH, Gumaste V V., Sharara AI. Systematic review and meta-analysis: adalimumab monotherapy versus combination therapy with immunomodulators for induction and maintenance of remission and response in patients with Crohn's disease. Inflamm Bowel Dis. (2017) 23:1316-27. doi: 10.1097/MIB.0000000000001203

144. Kamm MA, Hanauer SB, Rutgeerts P, Colombel J-F, Sandborn WJ, Lomax KG, et al. W1096 results from an open-label extension of CHARM: steroid-free remission in patients with Crohn's disease who received adalimumab therapy for at least 3 years. Gastroenterology. (2009) 136:A653. doi: 10.1016/S0016-5085(09)63010-9

145. Oussalah A, Chevaux J-B, Fay R, Sandborn WJ, Bigard M-A, PeyrinBiroulet L. Predictors of infliximab failure after azathioprine withdrawal in Crohn's disease treated with combination therapy. Am J Gastroenterol. (2010) 105:1142-9. doi: 10.1038/ajg.2010.158

146. Sokol H, Seksik P, Carrat F, Nion-Larmurier I, Vienne A, Beaugerie L, et al. Usefulness of co-treatment with immunomodulators in patients with inflammatory bowel disease treated with scheduled infliximab maintenance therapy. Gut. (2010) 59:1363-8. doi: 10.1136/gut.2010. 212712

147. Kierkuś J, Iwańczak B, Wegner A, Dadalski M, Grzybowska-Chlebowczyk $\mathrm{U}$, Łazowska I, et al. Monotherapy with infliximab versus combination therapy in the maintenance of clinical remission in children with moderate 
to severe Crohn disease. J Pediatr Gastroenterol Nutr. (2015) 60:5805. doi: 10.1097/MPG.0000000000000684

148. Filippi J, Laharie D, Michiels C, Flamand M, Bouguen G, Nancey S, et al. Efficacy of sustained combination therapy for at least 6 months with thiopurines and infliximab in patients with ulcerative colitis in clinical remission: a retrospective multicenter French experience. J Crohns Colitis. (2015) 9:252-8. doi: 10.1093/ecco-jcc/jjv001

149. Lambrescak E, Vaysse T, Allez M, Ungar B, Gleizes A, Hacein-Bey S, et al. Duration of combination therapy and risk of treatment failure in patients with inflammatory bowel disease. Clin Res Hepatol Gastroenterol. (2021) 45:101503. doi: 10.1016/j.clinre.2020.07.008
Conflict of Interest: The authors declare that the research was conducted in the absence of any commercial or financial relationships that could be construed as a potential conflict of interest.

Copyright (C) 2021 Gargallo-Puyuelo, Laredo and Gomollón. This is an open-access article distributed under the terms of the Creative Commons Attribution License (CC $B Y)$. The use, distribution or reproduction in other forums is permitted, provided the original author(s) and the copyright owner(s) are credited and that the original publication in this journal is cited, in accordance with accepted academic practice. No use, distribution or reproduction is permitted which does not comply with these terms. 